\title{
SERIAL ENDOSYMBIOTIC THEORY (SET): THE BIOSEMIOTIC UPDATE
}

\author{
Günther Witzany \\ telos - Philosophische Praxis, Vogelsangstr. 18c, A-5111-Buermoos/Salzburg, Austria \\ E-mail: witzany@sbg.at
}

Received 22 October 2005; accepted in final form 7 March 2006

\begin{abstract}
The Serial Endosymbiotic Theory explains the origin of nucleated eukaryotic cells by a merging of archaebacterial and eubacterial cells. The paradigmatic change is that the driving force behind evolution is not ramification but merging. Lynn Margulis describes the symbiogenetic processes in the language of mechanistic biology in such terms as "merging", "fusion", and "incorporation". Biosemiotics argues that all cell-cell interactions are (rule-governed) sign-mediated interactions, i.e., communication processes. As the description of plant communication demonstrates, the biosemiotic approach is not limited to the level of molecular biology, but is also helpful in examining all sign-mediated interactions between organisms on the phenotypic level. If biosemiotics also uses the notions of "language" and "communication" to describe non-human sign-mediated interactions, then the underlying scientific justification of such usage should be critically considered. Therefore, I summarize the history of this discussion held between 1920 and 1980 and present its result, the pragmatic turn.
\end{abstract}

Key Words: symbiogenesis, biosemiotics, genome editing competence, pragmatic turn, abstractive fallacy

\section{INTRODUCTION}

The Serial Endosymbiotic Theory explains the origin of nucleated eukaryotic cells by a merging of archaebacterial and eubacterial cells in anaerobic symbiosis, historically followed by acquisition of mitochondria or plastids. Thus, in contrast to former evolutionary theories which consider ramification as a driving force of evolution, there is a paradigmatic change bringing merging into the forefront of the discussion.

Lynn Margulis describes the symbiogenetic processes in the language of mechanistic biology in such terms as "merging", "fusion", "incorporation", and "amalgamation". Biosemiotics argues that all cell-cell interactions are rule-governed sign-mediated interactions, i.e., communication processes. The possibility to investigate plant communication demonstrates that the biosemiotic approach is not limited to the level of molecular biology, but is also helpful in examining all rule-governed sign-mediated interactions between organisms on the phenotypic level.

If biosemiotics also uses the notions of "language" and "communication" to describe non-human sign-mediated interactions, then the underlying scientific justification of such usage should be critically considered. Therefore, I summarize the history of this discussion held between 1920 and 1980 and present its result, the pragmatic turn. Pragmatic philosophy of biology, the pragmatic turn within it, has laid the foundation of a three-leveled 
biosemiotics and has justified it. It helps to avoid an abstractive fallacy - recurring weakness of today's scientific methodologies.

To extend the Serial Endosymbiotic Theory through a biosemiotic perspective I will follow eight steps as outlined in the following:

The first step is that I briefly present the aims of biosemiotics. Biosemiotics investigates life processes, and more concretely, sign use within and between organisms. Biosemiotics holds that no life processes could be coordinated and organized without signs.

The second step is the outline of the Serial Endosymbiotic Theory. As Lynn Margulis plausibly demonstrates, chance mutations were not responsible for initiating the evolutionary process from prokaryotes to eukaryotes. Rather, merging processes by various prokaryotes - via endosymbioses and the fusion of different organisms - ultimately led to a eukaryotic cell.

The third step allows me to show that these merging processes go beyond mere changes in the chemical/physical state of these cells. Lynn Margulis uses her terms to describe these processes: merging, fusion, incorporation, amalgamation. However, I argue that the symbiogenetic integration of different genomes into a single genome is not a chance merging or fusion process, but rather it requires precise and error-free DNA/RNA processing, not the chance integration of DNA components, but rather the integration of entire gene blocks along with their phenotypic features.

The fourth step shows that competent DNA-processing underlies semiotic rules. Traditionally we have assumed that such nucleic acid processing could only be carried out by enzyme proteins: they were known to be responsible for key DNA modification processes such as DNA splicing, RNA editing, coding, copying, major and fine repair, transcription, translation, etc. They were considered unlikely candidates for evolutionary genome editing. This would have created a paradox that there had to be a DNA that coded for proteins that changed their own DNA-template, as Watson formulated ("Enzymes cannot determine the order of the amino acids in polypeptide chains", Watson et al., 1992: 6). Here, I show that this genome-editing competence, with its higher-order regulatory function, was found not in the protein-coding DNA (as it was previously thought), but in the non-protein-coding DNA (long-termed insignificant "junk DNA").

The fifth step covers the example with plants where I show that the biosemiotic thesis, namely that sign-mediated interactions are the central aspect in coordinating and organizing life processes, is valid not only in the intracellular-genetic realm but also in the intercellular-organismic realm.

The sixth step demonstrates the necessity to specify the scientific basis for referring to language and communication in living nature. The history of science shows that the theoretical clarification of these two terms had two historical phases. The first was the linguistic turn and attempted to construct a language that could be applied to formulate exact statements in the natural sciences. During the second phase, the pragmatic turn, it became apparent that the attempt to justify such a language failed because the proponents had based their premises on an unrealistic model of language and the subject of knowledge.

The seventh step is my applying of a biosemiotic approach to biological processes (e.g. molecular biology, symbiogenesis, or phenotypic communication within and between plants) which requires considering all three semiotic levels of rules (pragmatics, syntax, semantics). A reductionistic abbreviation of these three levels irrevocably 
leads to an abstractive fallacy, for which there are numerous examples in the history of science.

The eighth step is an attempt to symbiologically expand the self-awareness of biologists. Pragmatic philosophy of biology could help to alter the process of self-awareness in biologists: they should comprehend themselves as biological entities who are permanently involved in symbiotic processes; even in scientific discourse, they are dependent participants in the indefinite dialogue within the scientific community.

\section{WHAT'S THE AIM OF BIOSEMIOTICS}

Biosemiotics is a transdisciplinary science including theoretical and empirical studies; it investigates the use of signs within and between organisms. Signs may be signals or symbols, most of them chemical molecules. In the highly developed eukaryotic kingdoms, behavioral patterns of organisms also may serve as signs (signals and/or symbols), as for example, the dances of bees; or the signs may be phonetic, as in songbirds or humans. The signs obey semiotic rules of three types. Syntactic rules determine combinatory possibilities - physical, chemical, spatial, temporal, rhythmical. Pragmatic rules determine interactional content (e.g., regulatory pathways have significant differences with metabolic pathways). And those rules dependent on pragmatic interactional content are the semantic ones, i.e., the meaning of signs and sign sequences (e.g. in signalling pathways).

Individuals in a population share a common set of signs and a common set of rules. It can be applied to cell biology as well. Dependent on the situational context of interacting entities, one sign, or sequence of signs, can have different meanings or functions. Therefore, it is possible that different cell types come from the same genome by the interpretation of different chromosomal methylation patterns. Biosemiotics in the context of molecular cell biology includes not only sign processes used within cells, but also embraces immunological, metabolic, neurological and hormonal signaling pathways.

Zoosemiotics is considered the forerunner of contemporary biosemiotics. Corresponding to the five taxonomic kingdoms zoosemiotics has been completed by prokaryotic semiotics (bacteria), protoctist semiotics (eukaryotic microorganisms), mycosemiotics (fungi) and phytosemiotics (plants) (Nöth, 2000). To many biosemioticians, the origin of life is the starting point of semiosis and vice versa (Witzany, 1993; Hoffmeyer,1996; Barbieri, 2001; Markos, 2002; Emmeche and Hoffmeyer, 2005; Pattee, 2005).

So far, biosemiotic terms have been used as metaphors in molecular and evolutionary biology, as well as in genetics and ecology, the conviction being that they could ultimately be replaced by chemical and physical descriptions. As a result, the paradigmatic differences between biosemiotic and chemical/physical descriptions are becoming much more evident, what enables biosemiotics to draw a clear distinction between the biotic and abiotic domains: "Life is distinguished from the nonliving world by its dependence on signs" (Pattee, 2005). Thereby, it is possible to use biosemiotics to expand the perspective on biological processes. Consequently, the factors decisive for life processes do not consist only of the states of matter and their corresponding changes based on natural laws, but also of the communication and information processes within and among cells, tissues, organs, organisms. Their importance determines the success or failure to promote life, growth, development, disease and death in all living beings. Biosemiotics 
enables a broader understanding of the complexity of life processes which could hardly be achieved by conventional biological methods.

\section{THE SERIAL ENDOSYMBIOTIC THEORY}

The Serial Endosymbiotic Theory is so revolutionary because it has reversed the evolution vector from ramification to merging. Eukaryotic cells, according to Margulis, are the result of merging several different ancestor genomes (Margulis, 1996, 1999, 2004; Margulis et al., 2000; Margulis and Sagan, 2002).

Margulis refers to the term symbiogenesis coined by Mereschkowsky and Wallin. The authors argue that new tissues, organs, organisms and species arise from entering into long-term, permanent symbioses. Bacteria were permanently incorporated into animal and plant cells as plastids and mitochondria (Searcy, 2003).

The important factor is the sequence of merging in symbiogenesis, i.e., the serial evolution. The first merger involved (1) thermoplasmic archaebacteria with motile spirochaeta-like eubacteria that (2) were able to swim, to the nucleocytoplasm. These forms were still anaerobic. Then merging with (3) aerobic organisms followed. This enabled them to survive the increasing oxygen concentrations. The final step was the merging with (4) photosynthetic bacteria. This approach of the Serial Endosymbiotic Theory contradicts traditional theories of evolution, all of which firmly held that the direction lay in ramification and not in merging.

Cilia, the rods in the retina, the tail of sperm cells, sensory hairs and many similar appendages of nucleated cells arose during the original merging of archaebacteria and a swimming bacterium. The bodies that contain so-called "centriole-kinetosomes" arose through this archaic merger. There is also a genetic relationship between cilia and microtubules at the surface of nuclei of plants, and between microtubules and the mitotic spindles responsible for chromosome movement during cell division. Baluska et al. (2004) have convincingly reconstructed this in their cell body theory. According to Margulis, the Spirochaeta are the modern, free-living relatives of these symbiogenetically merged centriole-kinetosomes.

One integrated genome was sufficient in the merger of archae-and eubacterium; in the Protoctista two integrated genomes were necessary, in the fungi - three, in animals - at least four, and in the plant kingdom (400 million years ago) - at least five, perhaps, even seven (Margulis, 1996). Thus, the plant genome is the epitome of symbiogenetic evolution processes and represents the most complex integration process. Considering that the evolution of flowering plants took place only about 150 million years ago, and that their seeds and fruits laid the foundation of higher animals, then these revolutionary symbiogenetic processes are relatively young compared with evolutionary history as such (Margulis and Schwartz, 1988).

The Serial Endosymbiotic Theory also supports Margulis's assumption by pointing out that most of the DNA found in the cytoplasm of protoctists, animals, fungi and plants come from genes of bacteria that became organelles, and not from genetic drift or mutations. Eukaryotic genes that participate in information processing (translation, transcription, etc.) show a close relationship to eubacteria. On the contrary, genetic factors that control metabolic processes more closely resemble the metabolic processes in archaebacteria. 
Another advantage of the merging paradigm of the Serial Endosymbiotic Theory is that DNA elongation (from bacterium to humans: $1-1000 \mathrm{~mm}$ ) need not be attributed to chance, which would be highly improbable (Vollmert, 1985), but rather to a merging of entire gene-blocks. This demonstrates that complex genomic make-ups can be passed on directly and that the step-by-step development via chance mutations is outdated. There are also strong indications that eukaryotic nucleus is of viral origin (Villarreal and DeFilippis, 2000; Bell, 2001; Ryan, 2002; Villarreal, 2004).

\section{MERGING? - COMMUNICATION!}

Lynn Margulis uses in the Serial Endosymbiotic Theory the classic language of mechanistic biology to describe the highly complex interactions of a symbiosis and, subsequently, symbiogenesis. This language ("merging", "fusion", "incorporation", etc.) is imprecise because it describes the altered state of matter, rather than the semiotic aspects of genome editing, i.e., the syntactic, pragmatic and semantic rules which determine combinatorial, interactional and functional aspects of the integration processes of different prokaryotic genomes into one.

In fact, a multi-leveled, generative DNA-processing rather than "fusion" is involved. Its success, however, depends on whether the necessary sign processes proceed according to rules or whether they fail. Moreover, the integration of genetic components into available genomes and, therefore, the creation of a new individual do not involve "incorporation", but rather rule-governed sign-mediated interactions between cells and cell components.

The pragmatic philosophy of biology (Witzany, 1993, 2000) and the young science of biosemiotics (Kull, 2005) demonstrate that life functions are always related to sign processes. More precisely, sign processes regulate and constitute life functions (Witzany, 1993, 2006; Hoffmeyer, 1996; Barbieri, 2001; Markos, 2002; Emmeche and Hoffmeyer, 2005; Pattee, 2005). If these sign processes are deformed or defective, then life processes are compromised or terminated. Sign processes regulate life processes on different levels simultaneously (Figure 1): intracellularly, within the cell (DNA, RNA activities, messenger substances, etc.), and intercellularly as cell-cell communication. This is the intraorganismic level. In parallel, each organism also conducts (speciesspecific) interorganismic and (trans-specific) metaorganismic communication processes (Witzany, 1993, 2000).

Should the symbiosis lead to a symbiogenesis, to the development of a new species and, thus, to the disappearance of the formerly independent individuals, then the result is generative DNA- processing in which genetically different gene pools are combined into one genome. This requires a recombination that assimilates the foreign data set, converting the external into the internal. Which genome editing competences are able to integrate an endosymbiotic genome in a host genome? Manfred Eigen would ask how we should think about the correct rearrangement of the "molecular syntax" (Witzany, 1995).

\section{SYMBIOGENESIS BY DNA/RNA PROCESSING}

Over the last 25 years, tens of thousands of papers have been published in the field of molecular biology, genetics, biochemistry, epigenetics and similar disciplines which outline in great detail the intracellular processes of recombinant DNA, splicing, self-splicing, 


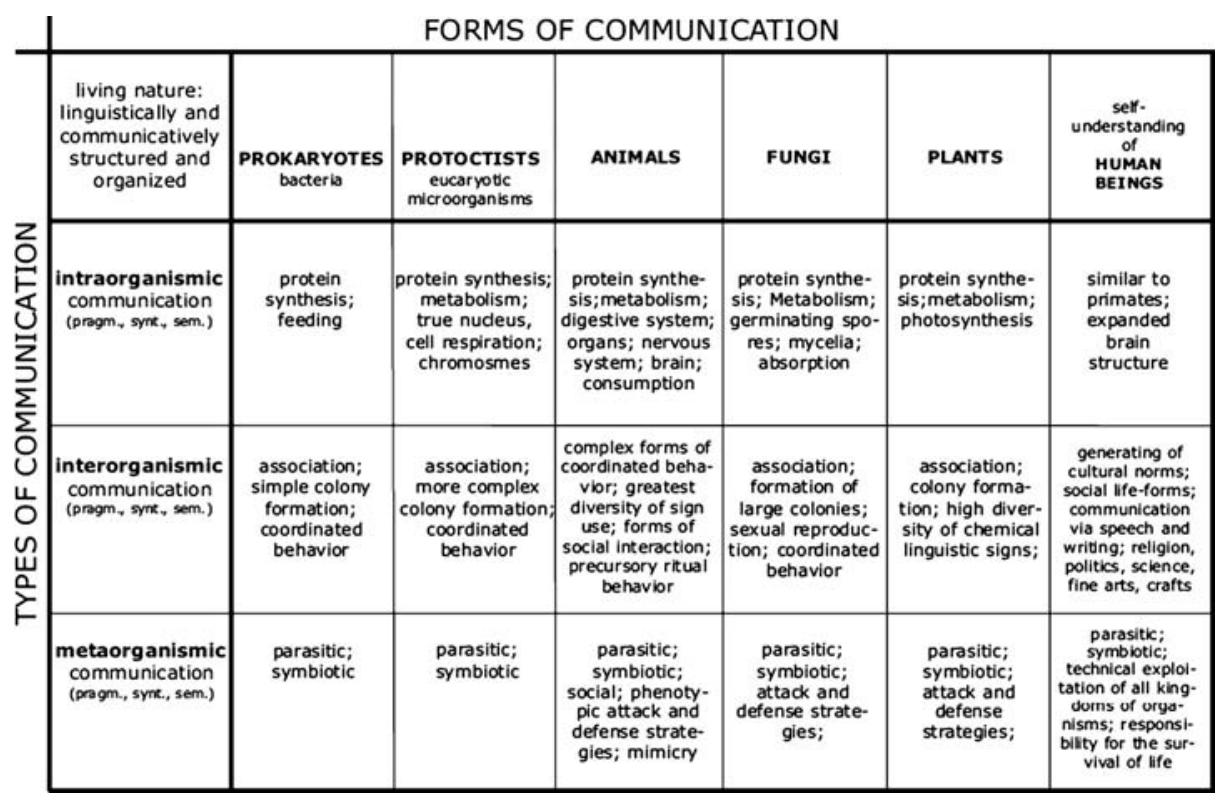

Figure 1. Types and forms of communication according to pragmatic philosophy of biology (Witzany, 2000).

RNA-editing, coding, copying, major and fine repairs, transcription, translation, RNA processing, insertion, the role of introns and exons in "reading" processes, the complementary roles of DNAs and RNAs, even the significance and indispensable structural function of non-coding DNA (Cavalier-Smith and Beaton, 1999; Sternberg, 2002; Jaenisch and Bird, 2003; Baluska et al., 2004; Shapiro and Sternberg, 2004; Schmitt and Paro, 2004; True et al., 2004; Wang et al., 2004).

Successful DNA/RNA processing requires numerous, specifically tailored enzyme proteins. In all cases, DNA/RNA-processing enzyme proteins and also interacting RNAs are involved in very precisely conducting these varied DNA-processing steps. Any mistakes here typically have serious and often lethal consequences for the organism.

Today there are strong evidences that this processing of protein-coding DNA is overruled by the genome processing abilities of DNA coding not for proteins but for active micro-RNAs (Mattick, 2001; Mattick and Gagen, 2001; Spotswood and Turner, 2002; Turner, 2002; Mattick, 2003, 2005; Shapiro and Sternberg, 2005). Especially, the recombination of two different genomes into one, as it happened in symbiogenesis, can be viewed through the text processing competences of active micro RNAs.

Active micro-RNAs control and integrate large-scale structures of the chromosome. The number of different micro-RNAs is estimated to exceed several tens of thousands. Some of the discovered tasks of these micro-RNAs are co-suppression, suppression of transposition, position effect variegation, start-stop signals, RNA interference, imprinting, chromosomal methylation, transvection, transcriptional/posttranscriptional gene silencing along with numerous other RNA-DNA, RNA-RNA (trans-acting RNAs), RNAprotein interactions. Additionally, these active RNAs are as competent as proteins in 
catalyzing, signalling and switching (Mattick, 2001; Mattick and Gagen, 2001; Mattick, 2003, 2005).

Cellular differentiation and phenotypic variation appear primarily from variations in this higher order regulation, not in the proteins themselves or in their mutations. The phenotypic variation in complex organisms is the result of a different use of a set of protein-coding core components. The higher order regulation in non-protein-coding genome architecture is able to manage a larger genetic data set in its phenotypic range. As far as evolutionary processes are concerned, it is naturally much simpler to change or expand a number of very small control sequences than to duplicate an entire network of protein-coding DNA (Sternberg, 2002; Shapiro and Sternberg, 2005). Variations of this higher order regulation can create an enormous spectrum of different protein expression profiles and we can understand why one and the same gene can be used for multiple protein meanings. New reports suggest that the capabilities of non-coding DNA with higher order regulatory functions in the genomes of higher eukaryotic taxa descend from ancestral viral genome-editing competences that have been integrated by endogenous retroviruses. While complete genetic functions are transferred to the nucleus after the persistent retroviral infections, the regulatory LTRs (Long Terminal Repeats) and other repetitive elements which flank the protein-coding genetic dataset are integrated in nonprotein-coding regions. In the human genome, several thousands of such events are documented (Bell, 2001; Ryan, 2002; Villarreal, 2004).

\section{PLANT MULTILEVEL COMMUNICATION COMPETENCE}

Biosemiotic aspects are not only interesting on the intracellular genetic and epigenetic level but also in analyzing sign-mediated interactions between cells of organisms, and between organismic bodies, e.g. plants. Plant scientists formerly thought of plants also in terms of mechanistic biology as automatons. Meanwhile research into the multilevel communication of plants revealed attributes like learning, memory, individuality and plasticity as an expression of so-called "plant intelligence" (Trewavas, 2003, 2004, 2005). During last 5 years plant research has also shown that the old dichotomy of chemical versus neuronal-electric communication is misinterpretation. Today we know that $99 \%$ of neuronal communication is based on chemical messenger substances, and that electric action potentials serve merely to maintain the transport of messenger substances by long neuronal tracts (Trewavas, 2003). Therefore, the catchword for new directions in plant biology is "plant neurobiology", not "plant physiology".

Plants represent a major success story in evolution and are the most recent organismic kingdom. Higher plants make up $99 \%$ of the eukaryotic biomass on our planet. At the same time, this success story also reflects the success of multilevel communicative actions by plants in their intra-, inter- and metaorganismic stages: it represents a crucial dependency on successful communication with microbial communities (Walker et al., 2003; Bais et al., 2004), with fungi (especially in the rhizosphere), with animals (especially with insects), and, in parallel, the multilevel communication processes in and between cells, tissues and the whole body (Trewavas, 2003).

The communication on the molecular level between plant tissue and the plant cells is exceptionally complex and encompasses nucleic acids, oligonucleotides, proteins and peptides, minerals, oxidative signals, gases, hydraulic and mechanical signals, electric 
signals, fatty acids, oligosaccharides, growth regulators, amino acids, numerous secondary products, simple sugars, and many other as yet unstudied aspects (Baluska et al., 2006).

\section{LANGUAGE AND COMMUNICATION: FROM LINGUISTIC TURN TO PRAGMATIC TURN}

For more than 10 years, most biological disciplines have increasingly been referring to "communication" and "language" in describing and explaining interactions in and between cells, between tissues and organs, whole bodies, organisms, species-specific and trans-species interactions. The influence of a linguistic vocabulary is omnipresent and has become irreplaceable. This calls for an up-to-date definition of "language" and "communication" if we want to avoid using these terms in an uncritical, precipitate or merely metaphorical manner.

In referring to the language of life, to nucleic- and amino acid codes, and to communication in linguistic terminology in order to describe essential life processes, we can rely on an unspoken and uncritical pre-understanding of language and communication, i.e., on metaphysical and/or reductionistic prerequisites: We can say that (1.) we are working in standardized experimental setups and, hence, theoretical preconditions are not very interesting. We can say that (2.) we refer to the world of objects in the language of exact natural science whose validity claim is founded on the laws of the physical world. We might assume that (3.) observed things have a direct empirical significance that does not need to be questioned further on because there is one-to-one correspondence of the physical laws with the material foundations of the linguistically constructive human brain (universal syntax). We might also assume (4.) an overlying meta-system in which human populations represent one of the subsystems that communicates within itself and with co-systems in an information-theoretical framework (Witzany, 1995, 1998, 2002).

This suddenly puts us directly in the midst of a 60-year-long discussion about the theory of science held from approximately 1920 to 1980. It consisted of two phases, and its first result was (a) the linguistic turn, and the second result being (b) the pragmatic turn.

(a) The linguistic turn was the result of an attempt to separate the logic of science from philosophy and other "unscientific" cognitive methods. In the aftermath of Wittgenstein's "Tractatus logico-philosophicus", the "Wiener Kreis" around Carnap, Neurath, Feigl, Waismann, Kraft, Frank, Menger, Gödel, Hahn and in further developmental stages also Russel and Tarski held that no subjective phenomenology, philosophy or similar discipline could provide a suitable logic for an exact natural science; except the protocol propositions of observations reproducible in experimental setups which were capable of depicting reality on a one-to-one basis; it should be also valid for propositions of the language of a theory, that would have to be brought into agreement with these protocol propositions.

What is required is a language that can be formalized, e.g. as logical calculations, algorithms. This language would represent universal syntax that would be universally valid (i) for the things of the external world, (ii) for the physical laws and (iii) for the material reality of the brain of humans speaking in formalizable propositions (Witzany, 
1995). ${ }^{1}$ The history of science clearly documents the course of this discussion. Logical empiricism had to abandon its efforts to achieve the ultimate validity claim of a physicalistic universal language. Concepts such as empirical significance, initial and marginal conditions, verification und falsification, but above all the disposition terms, could not be adequately derived. Even the concept of "natural law" was justifiable only under the assumption of an arbitrary experimental design that presupposed a free will. Thus, the strongest, centuries-long argument against free will - the determinism of the material world - principally needed autonomous researchers if the term "natural law" was to be used justifiable in the natural sciences (Witzany, 1995).

(b) In fact, the transition from the linguistic turn to the pragmatic turn has already occurred in Wittgenstein's "Philosophical Investigations" and in his analysis of obeying (following) rules:

"Is what we call 'obeying a rule' something that it would be possible for only one man to do, and to do only once in his life? (...) It is not possible that there should have been only one occasion on which someone obeyed a rule. It is not possible that there should have been only one occasion on which a report was made, an order given or understood, and so on - To obey a rule, to make a report, to give an order, to play a game of chess, are customs (uses, institutions). To understand a sentence means to understand a language. To understand a language means to be master of a technique." (Wittgenstein 1972: 80e)

In his analysis of the expression "to obey a rule", Wittgenstein provides proof that the identity of meanings logically depends on the ability to follow intersubjectively valid rules with at least one additional subject; there can be no identical meanings for the lone and lonesome subject. Communication is a form of social action.

Following Wittgenstein's analysis of rules, the theory-of-science discourse derived and justified scientific statements based on an intersubjective-communicative concept of language and communication. At the same time, it replaced the solipsistic subject of knowledge of subjectivism and objectivism with the "ultimate opinion" of an "indefinite community of investigators" of Peirce. The content of argumentation developed by (language-game) Wittgenstein, Austin, Searle, Apel, and Habermas proved the intersubjective-communicative character of thought, experience and research (the a priori of the linguistic community) and was therefore able to avoid the omnipresent subject-object dichotomy and its unavoidable consequences, solipsism and objectivism.

Before we can consider the terms "language" and "communication", we must understand the language of discussing these terms. We understand sentences in a language in which we are linguistically competent; we understand sentences in which the speaker presents propositions interconnected with validity claims. Intersubjective validity of scientific knowledge requires therefore linguistic communication of meaning and consensus formation via statements. We do not understand the ontology of natural phenomena or empirical observations, physiological processes, systems, physical principles, but rather

\footnotetext{
${ }^{1}$ The conviction of the possibility of an exact language of science was so deeply embedded - and this might serve as an example of the valuation of emotions in purportedly emotion-free objectivism - that, while it was refuted and ultimately rejected in the theoryof-science discourse and in the history of science, it was and continues to be considered valid in many standard sciences, curricula, underlying convictions.
} 
sentences and actions that underlie grammatical, semantic and pragmatic rules that we share with the members of a linguistic community. A prerequisite for understanding is therefore a historically evolved social lifeworld, which provides the basis for the historical development of the commonly shared language, i.e., a core set of signs which obey semiotic rules (Witzany, $2005 \mathrm{a}, \mathrm{b}$ ). This, however, means that problems with understanding can arise if we are unaware of the grammatical, semantic or pragmatic rules that an uttering individual is following. ${ }^{2}$

\section{A THREE-LEVELED SEMIOTICS AND CLASSICAL VARIATIONS OF THE "ABSTRACTIVE FALLACY"}

The pragmatic turn founded the intersubjective-communicative character of thought, experience and research and was therefore able to avoid the omnipresent subjectobject dichotomy and its unavoidable consequences, solipsism and objectivism or, how Thomas McCarthy characterized the monological (third-person) observer perspective: "The monological approach preordained certain ways of posing the basic problems of thought and action: subject versus object, reason versus sense, reason versus desire, mind versus body, self versus other, and so on" (McCarthy, 1984: ix). As opposed to the linguistic turn, the pragmatic turn enables an understanding of human language and communication that is coherent with our communicative experience and with our subjective life. Such an understanding of language and communication should allow

\footnotetext{
${ }^{2}$ In order to reach an understanding with another speaker and establish an interrelationship, four validity claims must be fulfilled: (1.) An utterance must be understandable. If the partner cannot understand the utterance, then he or she cannot answer (respond) appropriately. (2.) The utterance must be correct, i.e., the expressions used must be the correct ones to express the situation (normative rightness). (3.) It must be true - the expressed situation must correspond with reality (propositional truth), (4.) It must be sincere, i.e., be meant in the manner in which it was expressed.

The understanding of intersubjective acts of human communication is directed at three levels, on that of (a) linguistic utterances, (b) actions, and (c) body-embedded expressions. Linguistic utterances have an evident (locutionary) communicatory aspect. Depending on the intention, they can use this grammatically clearly visible structure to mean something different: This represents their not-immediately-evident (illocutionary) force, which prompts those who are addressed to react in one way or another to one and the same grammatical structure of an expression. And they are part of an (perlocutionary) action; perlocutionary acts are performed with the intention of producing a further effect.

We do not need third-person observations and experimental studies to understand how understanding functions. We can analyze the ordinary language that we ourselves use, in the first or second person, i.e., as a participant; here, we can find all the elements of linguistic and communicative action. Firstly, we can determine that utterances such as requests, orders, questions, insinuations, accusations, approvals, declarations, fabrications, etc. are regulative, imperative, expressive, objectifying, innovative, etc. actions with the intention of (a) establishing a commonly held understanding about something and (b) establishing an intersubjective relationship of action that enables a common, coordinated action or appropriate differentiation of labor (Witzany, 2005a).
} 
us to describe the intersubjective-communicative character of thought, experience and research in a non-reductionistic manner, as well as to describe the everyday prerequisites for successful communication, namely:

- the simultaneous understanding of identical meanings in two interacting partners, as expressed in successfully coordinated activity;

- the differentiation between deep and superficial grammar of a statement along with differentiation between locutionary, illocutionary and perlocutionary speech acts with which the statements are made;

- the differentiation between communication-oriented action and strategic manipulation of the communicating partners;

- the critical judgment of the validity being claimed when making a particular statement.

Only with such a (universal-) pragmatic concept of language and communication, one which is neither subjectivistic nor objectivistic-naturalistic, can we sensibly determine whether similar structural features exist in the non-human realm, i.e., interactions within and between organisms which are sign-mediated (signals, symbols) (Witzany, 1993, 2000). In the human world as well as in non-human living nature sign-use is not a solus ipse event but needs individuals who share a common set of signs and semiotic rules.

It therefore makes little sense to refer to sign use in the communication processes of plant or bacterial lifeworlds, all the while presupposing an objectivistic language and communication concept, and using an empirical methodological ideal to explain the evolution of communicative interactions from the amoeba to humans. This would lead to the dead-end of the solipsistic subject of knowledge and hopeless entanglement in the subject-object dichotomy of objectivism/physicalism/naturalism as described above by McCarthy.

The reverse pathway is correct, beginning with humans, and human selfunderstanding, which must be coherent with the used concepts of "language" and "communication".

The semiotics of Charles Sanders Peirce is helpful in this respect. It can provide the irreducible conditions for the appropriate analyses of sign-usage and linguistic communication via a three-leveled semiotics. ${ }^{3}$

According to Peirce, a sign (1) designates something (2) to an interpreter (3). Semiotics is therefore an irreducible three-leveled relation of syntactic, semantic and pragmatic rules. Each of the 3 elements of the sign function already presupposes in its function the other two. According to Peirce, all those who reduce this principally irreducible three-leveled relation to two or one level, have fallen victim to an abstractive fallacy. The most common of these are (Apel 1974):

- Signs (1) without the signified (some)thing (2) and without sign interpreter (3): it yields abstraction from the a priori of the linguistic community (i.e., the

\footnotetext{
${ }^{3}$ The decisive change versus Kant's solus-ipse subject of knowledge (and subsequently, the objectivism in logical empiricism) is the "community of interpretation" in the "community of investigators". Scientific knowledge does not exist for a solipsistic subject of knowledge but only for members of a community of interpreters. With this, Peirce adheres to the intersubjective-communicative character of thought, experience and research. (This is coherent with Wittgenstein's analyses of "obeying a rule".)
} 
intersubjective-communicative character of thought, experience and research as described above) which reflects on the world and produces propositions with validity claims. Examples are linguistic Platonism, model-Platonism of the logic of science in the linguistic turn in which the linguistic expressions or the explanatory model are the real (some) thing.

- The sign interpreter (3) without signs (1) and without the signified (some)thing (2): it yields idealism of consciousness; abstraction from the a priori of the linguistic community (Descartes, Kant, Fichte, Hegel, Husserl) - that is to say subjective/objective reason is the real (some)thing. Language is only a secondary means of explanation; the external world exists only through reason/rationality.

- Sign interpreter (3) and sign (1) without the signified (some)thing (2): this yields semiotic idealism: sign and sign interpreters are the signified (some)thing. Everything is a sign: Pansemiotics/metaphysical semioticism.

- The signified (some)thing (2) without signs (1) and without sign interpreter (3): This yields realism and materialism, pre-Kantian ontology/metaphysics: Being is a physical- chemical law of the material world. We are part of this particular material and can at best recognize approximately, with our sense organs, partial perspectives of this material being. Sign use and sign interpretation are pre-scientific constructions that lack a correspondence in the material world (illusion).

- The signified (some)thing (2) and the sign interpreter (3) without signs (1): it yields psychologism or affection-realism; Leibniz, Locke, Berkeley, Hume, positivism of the sensory data, Popper: the observational language and theoretical language of the logic of science can be brought into agreement. The material function of the sensory organs adheres to "universal syntax" that is identical to the laws of physics and chemistry.

- The signified (some)thing (2) and the sign (1) without the sign interpreter (3): it yields ontosemantic realism, constructivism, systems theory, information theory. Abstraction from the a priori of the linguistic community yields subjectless, syntacticsemantic phase of a modern science of logic in Carnap, Russel, Frege, (Tractatus-)Wittgenstein, Tarski, Popper; solipsism and realism: each speaker/listener is equipped with the same syntax (depicting material reality), alleviating any need for communication about the structure of language or the structure of the world. Abstraction by the cognizant subject produces scientifically exact statements which depict, in agreement with the laws of physics and chemistry, material reality on a one-to-one basis. Subjects of knowledge only disturb this naturalism and muddy the exact cognitive process.

\section{PRAGMATIC PHILOSOPHY OF BIOLOGY: BIOLOGISTS AS PERFORMATIVE PARTICIPANTS}

A pragmatic philosophy of biology is a philosophy of biology which integrates the irreducible three-leveled semiotics. This approach avoids the abstractive fallacy and allows us to understand language-like structured and communicatively organized living nature in a non-solipsistic, non-objectivistic manner. Therefore, it can methodologically strengthen the perspective of performative participants (first/second person perspective) of a planetary communicating community of living nature.

The pragmatic philosophy of biology enables a clear distinction between life and the non-living. The unbridgeable gap between a mechanistic and the communicative concept is that rule-governed sign-mediated interactions are restricted to living individuals 
(-in-populations) and are not determined by natural laws solely. The decisive difference between natural laws and semiotic rules is that every living being underlies natural laws in a strict sense, but semiotic rules may be followed or not, may be changed or not, may be generated or not. The fundamental difference between living nature and non-living nature is that life depends on sign-mediated interactions, i.e., communication processes which obey syntactic, pragmatic and semantic rules, whereas crystallization of water to ice, for example, requires solely natural laws rather than semiotic rules.

\section{REFERENCES}

Apel, K.O. (1974). Zur Idee einer transzendentalen Sprachpragmatik. Die Dreistelligkeit der Zeichenrelation und die "abstractive fallacy" in den Grundlagen der klassischen Transzendentalphilosophie und der sprachanalytischen Wissenschaftslogik. In Simon, J. (Ed.) Aspekte und Probleme der Sprachphilosophie. Verlag Karl Alber, Freiburg/München, pp. 283-326.

Austin, J.L. (1962). How to do things with words. Oxford University Press, Oxford.

Bais, H.P., S.W. Park, T.L. Weir, R.M. Callaway and J.M. Vivanco (2004). How plants communicate using the underground information superhighway. Trends in Plant Science 9: 26-32.

Baluska, F., D. Volkmann and P.W. Barlow (2004). Eukaryotic cells and their cell bodies: Cell theory revised. Annals of Botany 94: 9-32.

Baluska, F., D.Volkmann, A. Hlavacka, S. Mancuso and P.W. Barlow (Eds.) (2006). Communication in Plants. Springer Verlag, Berlin/Heidelberg.

Barbieri, M. (2001). The Organic Codes. The birth of semantic biology. Ancona: PeQuod.

Bell, P. (2001). Viral eukaryogenesis: Was the ancestor of the nucleus a complex DNA virus? Journal of Molecular Evolution 53: 251-256.

Cavalier-Smith, T. and M.J. Beaton (1999). The skeletal function of non-coding DNA: New evidence from ancient cell chimeras. Genetics 106: 3-13.

Emmeche, C. and J. Hoffmeyer (2005). Code-duality and the semiotics of nature. Journal of Biosemiotics 1: 27-64.

Habermas, J. (1979). Communication and Evolution of Society. Beacon Press, Boston.

Hoffmeyer, J. (1996). Signs of meaning in the Universe. Indiana University Press, Bloomington.

Jaenisch, R. and A. Bird (2003). Epigenetic regulation of gene expression: How the genome integrates intrinsic and environmental signals. Nature genetics supplement 33: 245-254.

Kull, K. (2005). A brief history of biosemiotics. Journal of Biosemiotics 1: 1-25.

Margulis, L. and K.V. Schwartz (1988). Five Kingdoms. W. H. Freeman and Company, New York.

Margulis, L. (1996). Archaeal-eubacterial mergers in the origin of Eukarya: Phylogenetic classification of life. Proceedings of the National Academy of Sciences of the USA 93: 1071-1076.

Margulis, L. (1999). Die andere Evolution. Spektrum Akademischer Verlag, Heidelberg.

Margulis, L., M.F. Dolan and R. Guerrero (2000). The chimeric eukaryote: Origin of the nucleus from the karyomastigont in an amitochondriate protists. Proceedings of the National Academy of Sciences of the USA 97: 6954-6959.

Margulis, L. and D. Sagan (2002). Acquiring genomes. A Theory of the Origin of Species. Basic Books, New York.

Margulis, L. (2004). Serial endosymbiotic theory (SET) and composite individuality. Transition from bacterial to eukaryotic genomes. Microbiology Today 31: 173-174.

Markos, A. (2002). Readers of the Book of Life. Oxford University Press, Oxford/New York.

Mattick, J.S. and M.J. Gagen (2001). The evolution of controlled multitasked gene networks: The role of introns and other noncoding RNAs in the development of complex organisms. Molecular Biology and Evolution 18: 1611-1630. 
Mattick, J.S. (2001). Non-coding RNAs: The architects of eukaryotic complexity. EMBO Reports 2: 986-991.

Mattick, J.S. (2003). Challenging the dogma: The hidden layer of noncoding RNAs in complex organisms. BioEssays 25: 930.

Mattick, J.S. (2005). Das verkannte Genom-Programm. Spektrum der Wissenschaft 3: 62-69.

McCarthy, T. (1984). Translator's introduction. In: Habermas, J., The Theory of Communicative Action 1, p. ix, Beacon Press, Boston.

Nöth, W. (2000). Handbuch der Semiotik. Metzler, Stuttgart.

Pattee, H.H. (2005). The physics and metaphysics of biosemiotics. Journal of Biosemiotics 1: $223-238$.

Ryan, F. (2002). Darwin's blind spot: evolution beyond natural selection. Houghton Mifflin Company, Boston.

Searcy, D.G. (2003). Metabolic integration during the evolutionary origin of mitochondria. Cell Research 13: 229-238.

Searle, J.R. (1976). Speech acts. An essay in the philosophy of language. Cambridge University Press.

Schmitt, S. and R. Paro (2004). A reason for reading nonsense. Nature 429: 510-511.

Shapiro, J.A. and R.V. Sternberg (2005). Why repetitive DNA is essential to genome function. Biological Review 80: 1-24.

Spotswood, H.T. and B.M. Turner (2002). An increasingly complex code. The Journal of Clinical Investigation 110: 577-582.

Sternberg, R.V. (2002). On the roles of repetitive DNA elements in the context of a unified genomic-epigenetic system. Annals of the New York Academy of Sciences 981: 154-188.

Trewavas, A. (2003). Aspects of plant intelligence. Annals of Botany 92: 1-20.

Trewavas, A. (2004). Aspects of plant intelligence: An Answer to Firn. Annals of Botany 93: 353-357.

Trewavas, A. (2005). Green plants as intelligent organisms. Trends in Plant Science 10: 413-419.

True, H.L., I. Berlin and S.L. Lindquist (2004). Epigenetic regulation of translation reveals hidden genetic variation to produce complex traits. Nature 431: 184-187.

Turner, B. M. (2002). Cellular memory and the histone code. Cell 111: 285-291.

Villarreal, L.P. and V.R. DeFilippis (2000). A hypothesis for DNA viruses as the origin of eukaryotic replication proteins. Journal of Virology 74: 7079-7084.

Villarreal, L.P. (2004). Can viruses make us humans? Proceedings of the American Philosophical Society 148: 296-323.

Vollmert, B. (1985). Das Molekül und das Leben. Rowohlt, Reinbeck.

Wang, Y., W. Fischle, W. Cheung, S. Jacobs, S. Khorasanizadeh and C.D. Allis (2004). Beyond the double helix: Writing and reading the histone code. In: Bock, G. and Goode, J. (Eds.) Reversible Protein Acetylation. Novartis Foundation, 2004.

Walker, T.S. (2003). Root exudation and rhizosphere biology. Plant Physiology 132: 44-51.

Watson, J. D., M. Gilman, J. Witkowski and M. Zoller (2 1992). Recombinant DNA. W.H. Freeman and Company, New York.

Wittgenstein, L. (1972). Philosophical Investigations. Basil \& Blackwell, Oxford.

Witzany, G. (1993). Natur der Sprache - Sprache der Natur. Sprachpragmatische Philosophie der Biologie. Königshausen \& Neumann, Würzburg.

Witzany, G. (1995). From the "logic of the molecular syntax" to molecular pragmatism. Evolution and Cognition 1: 148-168.

Witzany, G. (1998). Explaining and understanding LIFE. Semiotica, 120: 421-438.

Witzany, G. (2000). Life: The communicative structure. A New Philosophy of Biology. Libri Books on Demand, Norderstedt. 
Witzany, G. (2002). Reduction of biological phenomena? Deficits of systems theory and the alternatives. In: Schmitz, W. (Ed.), Sign Processes in Complex Systems, Mouton de Gruyter, Berlin/New York, 303-307.

Witzany, G. (2005a). From biosphere to semiosphere to social lifeworlds. Biology as an understanding social science. TripleC-Cognition, Communication, Cooperation 3: 51-74.

Witzany, G. (2005b). Natural history of life: History of communication logics and dynamics. S.E.E.D. Journal 5: 27-55.

Witzany, G. (2006). The Logos of the Bios 1. Contributions to the foundation of a three-leveled Biosemiotics. Umweb, Helsinki. 